\title{
Perineal Artery
}

National Cancer Institute

\section{Source}

National Cancer Institute. Perineal Artery. NCI Thesaurus. Code C52994.

An artery arising from the internal pudendal artery that supplies the bulbocavernosus and ischiocavernosus muscles of the perineum. 